\title{
Metastatic Gastroesophageal Adenocarcinoma Patients Treated with Systemic Therapy Followed by Consolidative Local Therapy: A Nomogram Associated with Long-Term Survivors
}

\author{
Hironori Shiozaki $^{a}$ Rebecca S. Slack ${ }^{b}$ Hsiang-Chun Chen ${ }^{b}$ Elena Elimova ${ }^{a}$ \\ Venkatram Planjery ${ }^{a}$ Nick Charalampakis ${ }^{a}$ Roopma Wadhwa ${ }^{a}$ \\ Yusuke Shimodaira $^{a}$ Heath Skinner $^{c}$ Jeffrey H. Lee ${ }^{d}$ Brian Weston ${ }^{d}$ \\ Manoop S. Bhutani ${ }^{d}$ Mariela Blum-Murphy ${ }^{a}$ Jane E. Rogers ${ }^{\text {e Dipen M. Maru }}{ }^{f}$ \\ Aurelio Matamoros Jr. ${ }^{g}$ Tara Sagebielg Jeannelyn S. Estrella ${ }^{f}$ Prajnan Das ${ }^{c}$

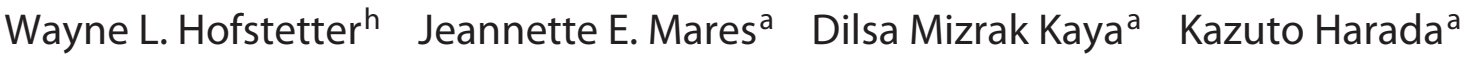 \\ Quan Lin $^{a}$ Bruce D. Minsky ${ }^{c}$ Brian D. Badgwell ${ }^{i}$ Jaffer A. Ajania \\ Departments of a Gastrointestinal Medical Oncology, ${ }^{\mathrm{b}}$ Biostatistics, ${ }^{\mathrm{c}}$ Radiation Oncology, ${ }^{\mathrm{d}}$ Gastroenterology, \\ ePharmacy Clinical Programs, ${ }^{\mathrm{f}}$ Pathology, ${ }^{\mathrm{g}}$ Radiology, ${ }^{\mathrm{h}}$ Thoracic and Cardiovascular Surgery, and 'Surgical \\ Oncology, University of Texas MD Anderson Cancer Center, Houston, Tex., USA
}

\section{Key Words}

Metastatic gastroesophageal adenocarcinoma .

Consolidative local therapy · Systemic therapy ·

Overall survival

\begin{abstract}
Objective: Patients with metastatic gastroesophageal adenocarcinoma (MGEAC) have a poor but heterogeneous clinical course. Some patients have an unusually favorable outcome. We sought to identify clinical variables associated with more favorable outcomes. Methods: Of 246 patients with MGEAC, we identified 64 who received systemic therapy and eventually received local consolidation therapy. Univariate and multivariate Cox regression models were used,
\end{abstract}

and a nomogram was developed. Results: Of these 64 patients, $61 \%$ had received consolidation chemoradiation (CRT) with doses of 50-55 Gy and 78\% did not undergo surgery. The median follow-up time of survivors was 3.9 years, and the median overall survival (OS) from CRT start was 1.5 years (95\% Cl, 1.2-2.2). Surgery (as local consolidation) was an independent prognosticator for longer OS in the multivariate analysis $(p=0.02)$. The 5 -year OS rate was $25 \%$ (SE = $6 \%)$. The contributors to the nomogram were longer duration of systemic therapy before CRT and the type of local therapy. Conclusions: Our data suggest that a subset of patients with MGEAC have an excellent prognosis (OS > 5 years). However, these patients need to be identified during their clinical course so that local consolidation (CRT, surgery, or both) may be offered.

(c) 2016 S. Karger AG, Basel

\section{KARGER}

E-Mail karger@karger.com www.karger.com/ocl
(C) 2016 S. Karger AG, Basel

0030-2414/16/0911-0055\$39.50/0
Dr. Jaffer A. Ajani

Department of Gastrointestinal Medical Oncology University of Texas MD Anderson Cancer Center 1515 Holcombe Blvd, (FC10.3022), Houston, TX 77030 (USA)

E-Mail jajani@mdanderson.org 


\section{Introduction}

In 2015, the American Cancer Society estimated that the number of new cases and deaths from esophageal cancer will be around16,980 and 15,590, respectively, and those from gastric cancer around 24,590 and 10,720, respectively, in the United States [1,2]. The 5-year overall survival (OS) rate of patients with distant metastasis, however, is only $4 \%[1,2,3]$. Nevertheless, some patients with metastatic gastroesophageal adenocarcinoma (MGEAC) survive beyond 5 years.

The standard of care therapy for patients with MGEAC is palliative systemic therapy combined with best supportive care $[4,5]$. This approach has considerable limitations but it can produce dramatic tumor regression in some patients [6,7]. Whether such patients should receive consolidative local therapies [such as chemoradiation (CRT) and/or surgery] is unclear. It may be much less important to know if local therapy is technically feasible in MGEAC patients at some point in their clinical course than when local therapy should be recommended so that patients derive the highest benefits from it. Currently, there is no established algorithm, and the published literature does not provide clear guidance. First principles would dictate that local therapy in patients with MGEAC should be delayed because if it is offered early (e.g., within 6 months of the start of systemic therapy), there remains a considerable risk of the manifestation of additional metastatic disease.

The purpose of this study is to identify clinical features that may help select patients who are likely to benefit from eventual local therapy. We also establish a nomogram to make it potentially a practical endeavor [8].

\section{Patients and Methods}

\section{Patients}

From our database of the Department of Gastrointestinal Medical Oncology at University of Texas MD Anderson Cancer Center (UTMDACC), we identified 246 consecutive patients with MGEAC between 2003 and 2014. Of these, 64 had received local 'consolidation' therapy and were the subjects of this analysis. All patients had adenocarcinoma of the esophagus, gastroesophageal junction, or stomach, and each patient had documented metastases (stage IV). All patients were staged by standard methods, and the stages were assigned by the American Joint Committee on Cancer (AJCC) 6th edition [9]. Prior to receiving any local therapy, each patient was discussed in the multidisciplinary conference to develop a consensus. Some patients were discussed more than once.

\section{Treatment and Follow-Up}

All 64 patients received systemic therapy for at least 6 months before being considered for local therapy. The preferred local therapy was CRT because of the morbidity associated with surgery. Chemotherapy included a fluoropyrimidine (intravenous or oral) and either a platinum compound or a taxane. The dose of radiation ranged from 45 to $65 \mathrm{~Gy}$ and was delivered in 25-28 fractions. Surgery, when agreed upon, was performed 6-8 weeks after the end of CRT. The chemotherapy regimen, radiation dose, and surgical techniques were at the discretion of the treating physician or surgeon.

After local therapy had been completed, patients were followed at 3- to 6-month intervals in the first 3 years and then less frequently.

\section{Survival}

The date of death was identified based on electronic health records, tumor registry, or the Social Security Database.

\section{Statistical Methods}

Patient characteristics were summarized using descriptive statistics. OS was defined as the number of years between the date of CRT start and that of death from any cause and was deleted at the last follow-up for living patients. Survival curves were estimated using the Kaplan-Meier method [10], and the median time was reported with a $95 \%$ CI. Univariate and multivariate Cox proportional hazards regression models [11] were used to assess the association between patient characteristics and OS. Surgery was treated as a time-varying covariate, changing from the 'No' group to the 'Yes' group on the date of surgery. The duration of chemotherapy and any patient characteristics that were significant in the univariate model at the 0.10 level were included in a multivariate model (full model). Duration of chemotherapy was required to remain in the multivariate model regardless of significance level. Then, backward elimination was implemented until all remaining predictors had a p value $<0.05$ (reduced model). A nomogram [12] was built to predict OS based on univariate Cox analyses for information available at the start of CRT, including patient characteristics that were significant at the 0.10 level. Discrimination was evaluated using the concordance index (C-index), with 200 bootstrap samples. Statistical analyses were performed with SAS 9.3 (The SAS Institute, Cary, N.C., USA), figures were created in Stata 13.1 (Stata Corp., College Station, Tex., USA), and the nomogram was created in S-plus (TIBCO Corporation, Palo Alto, Calif., USA).

\section{Statement of Ethics}

The Institutional Review Board of the UTMDACC approved this analysis.

\section{Results}

\section{Patient Characteristics}

A total of 64 patients with MGEAC who received local consolidation after systemic chemotherapy were identified. Table 1 shows that the patients were primarily men (81\%), with poorly differentiated MGEAC (63\%), good 


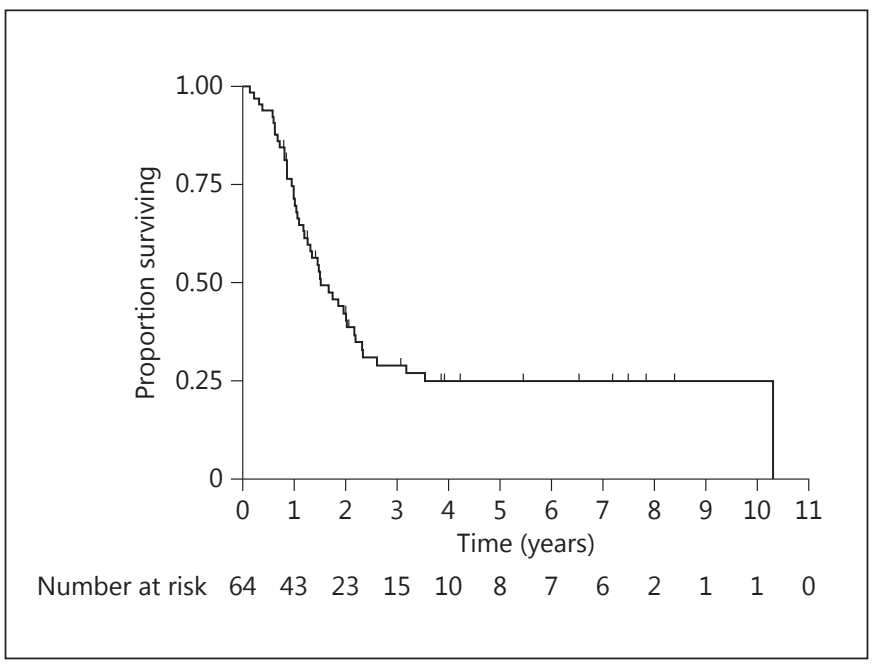

Fig. 1. OS rate.

Eastern Cooperative Oncology Group Performance Scores $\leq 1(90 \%)$, and distant lymph node metastasis (52\%), who received CRT with a dose range of 50-55 Gy $(61 \%)$ and did not undergo surgery $(78 \%)$.

\section{Overall Survival}

The median follow-up time for survivors was 3.9 years (range $0.8-8.4$ ). Forty-five (70\%) of 64 patients died, and $19(30 \%)$ were alive at the last follow-up. The median OS was 1.5 years (95\% CI 1.2-2.2), and the 1-year OS rate was $71 \%(\mathrm{SE}=6)$. The 5 -year OS rate was $25 \%(\mathrm{SE}=6$; fig. 1). Table 2 shows additional OS information. Only surgery $(\mathrm{p}=0.03)$ was significantly associated with OS. Ninety-two percent of the patients who had surgery and $67 \%$ of the patients who did not have surgery were alive at 1 year.

Table 3 shows the multivariate analysis of OS. The duration of chemotherapy before CRT, dose of consolidation CRT, and dose of surgery were included in the full model. The duration of chemotherapy was required to remain in the model, and only surgery remained significant in the reduced model. Patients with surgery were $63 \%$ less likely to die than those without surgery $(\mathrm{HR}=$ $0.37 ; \mathrm{p}=0.02$ ) after accounting for chemotherapy duration and including surgery as a time-varying covariate.

\section{Nomogram}

A nomogram (fig. 2) was developed to predict OS. The predictors included the duration of chemotherapy and dose of consolidation since they had $p$ values $<0.10$ and were readily available before CRT. The 'total points' cor-
Table 1. Patient characteristics

\begin{tabular}{|c|c|}
\hline \multicolumn{2}{|l|}{ At diagnosis } \\
\hline Age at presentation at UTMDACC $(\mathrm{n}=64)$ & $58(32,75)$ \\
\hline Chemotherapy duration, months $(\mathrm{n}=64)$ & $3.7(0.9,14.1)$ \\
\hline Primary tumor SUV at baseline $(\mathrm{n}=46)$ & $13.6(0,50)$ \\
\hline \multicolumn{2}{|l|}{ Primary tumor SUV after chemotherapy } \\
\hline$(\mathrm{n}=38)$ & $5.7(0,42)$ \\
\hline \multicolumn{2}{|l|}{ Gender } \\
\hline Male & $52(81)$ \\
\hline Female & $12(19)$ \\
\hline \multicolumn{2}{|l|}{ Histology grade } \\
\hline G2 moderately differentiated & $24(38)$ \\
\hline G3 poorly differentiated & $40(63)$ \\
\hline \multicolumn{2}{|l|}{ ECOG PS } \\
\hline 0 & $20(31)$ \\
\hline 1 & $38(59)$ \\
\hline 2 & $4(6)$ \\
\hline Missing & $2(3)$ \\
\hline \multicolumn{2}{|l|}{ Location of tumor } \\
\hline Esophagus & $6(9)$ \\
\hline AEG 1 & $16(25)$ \\
\hline AEG 2 & $15(23)$ \\
\hline AEG 3 & $13(20)$ \\
\hline Gastric & $14(22)$ \\
\hline \multicolumn{2}{|l|}{ Distribution of distant metastasis } \\
\hline Cytology & $13(20)$ \\
\hline Peritoneum & $9(14)$ \\
\hline Distant lymph nodes & $33(52)$ \\
\hline Peritoneum and distant lymph nodes & $1(2)$ \\
\hline Visceral & $8(13)$ \\
\hline \multicolumn{2}{|l|}{ HER2 } \\
\hline Positive & $3(5)$ \\
\hline Negative & $27(42)$ \\
\hline $\mathrm{N} / \mathrm{S}$ & $34(53)$ \\
\hline \multicolumn{2}{|l|}{ Adenocarcinoma subtype } \\
\hline SRC & $10(16)$ \\
\hline $\mathrm{M}$ and SRC & $2(3)$ \\
\hline $\mathrm{NE}$ & $2(3)$ \\
\hline NOS & $50(78)$ \\
\hline
\end{tabular}

Treatment

Dose of consolidation

$\begin{array}{lc}40-50 \text { Gy } & 21(33) \\ 50-55 \text { Gy } & 39(61) \\ >55 \text { Gy } & 3(5) \\ \text { Unknown } & 1(2) \\ \text { rgery } & \\ \text { Yes } & 14(22) \\ \text { No } & 50(78)\end{array}$

Values are median (min, max) or $\mathrm{n}(\%)$. AEG 1 = Esophageal carcinoma; AEG 2 = gastroesophageal junction carcinoma; AEG 3 = cardia/fundus gastric carcinoma; SUV = standardized uptake value; ECOG PS = Eastern Cooperative Oncology Group Performance Score; HER2 = human epidermal growth factor receptor 2; $\mathrm{SRC}=$ signet ring carcinoma; $\mathrm{M}=$ mucinous; $\mathrm{NE}=$ neuroendocrine; NOS $=$ not otherwise specified. 
Table 2. Univariate analysis of survival outcomes by patient characteristics $(n=64)$

\begin{tabular}{|c|c|c|c|}
\hline & OS & & \\
\hline & deaths/total & 1 -year (SE), \% & $\mathrm{p}$ value \\
\hline All patients & $45 / 64$ & $71(6)$ & \\
\hline Age* $^{*}$ & & & 0.45 \\
\hline$<60$ years & $23 / 37$ & $75(7)$ & \\
\hline$\geq 60$ years & $22 / 27$ & $65(9)$ & \\
\hline Chemotherapy duration* & & & 0.15 \\
\hline$<4$ months & $29 / 38$ & $68(8)$ & \\
\hline$\geq 4$ months & $16 / 26$ & $74(9)$ & \\
\hline $\log$ (primary tumor SUV at & & & \\
\hline baseline)* & & & 0.76 \\
\hline$<2.61$ & $17 / 22$ & $72(10)$ & \\
\hline$\geq 2.61$ & $19 / 24$ & $62(10)$ & \\
\hline log (primary tumor SUV after & & & \\
\hline chemotherapy)* & & & 0.30 \\
\hline$<1.74$ & $10 / 19$ & $78(10)$ & \\
\hline$\geq 1.74$ & $16 / 19$ & $62(11)$ & \\
\hline Gender & & & 0.20 \\
\hline Male & $38 / 52$ & $66(7)$ & \\
\hline Female & $7 / 12$ & $92(8)$ & \\
\hline Histology grade & & & 0.76 \\
\hline G2 moderately differentiated & $17 / 24$ & $62(10)$ & \\
\hline G3 poorly differentiated & $28 / 40$ & $77(7)$ & \\
\hline ECOG PS & & & 0.83 \\
\hline 0 & $13 / 20$ & $70(10)$ & \\
\hline$\geq 1$ & $31 / 42$ & $70(7)$ & \\
\hline Location of tumor & & & 0.11 \\
\hline Esophagus/AEG 1/AEG 2 & $28 / 37$ & $62(8)$ & \\
\hline Gastric/AEG 3 & $17 / 27$ & $85(7)$ & \\
\hline Distribution of distant metastases & & & 0.86 \\
\hline Cytology & $9 / 13$ & $68(13)$ & \\
\hline Distant lymph node & $24 / 33$ & $72(8)$ & \\
\hline Peritoneum/peritoneum & & & \\
\hline + distant lymph node & $7 / 10$ & $70(14)$ & \\
\hline Visceral & $5 / 8$ & $71(17)$ & \\
\hline Adenocarcinoma subgroup & & & 0.40 \\
\hline $\mathrm{SRC} / \mathrm{M}$ and SRC & $9 / 12$ & $64(14)$ & \\
\hline NE/NOS & $36 / 52$ & $73(6)$ & \\
\hline Type of consolidation & & & 0.08 \\
\hline $40-50$ Gy & $11 / 21$ & $90(7)$ & \\
\hline$>50 \mathrm{~Gy}$ & $33 / 42$ & $62(7)$ & \\
\hline Surgery ${ }^{1}$ & & & 0.03 \\
\hline Yes & $8 / 14$ & $92(7)$ & \\
\hline No & $37 / 64$ & $67(7)$ & \\
\hline
\end{tabular}

SUV = Standardized uptake value; ECOG PS = Eastern Cooperative Oncology Group Performance Score; AEG 1 = esophageal carcinoma; AEG 2 = gastroesophageal junction carcinoma; AEG 3 = cardia/fundus gastric carcinoma; $\mathrm{SRC}=$ signet ring carcinoma; $\mathrm{M}=$ mucinous; $\mathrm{NE}=$ neuroendocrine; $\mathrm{NOS}=$ not otherwise specified. ${ }^{*}$ p values were calculated based on continuous values for age at presentation at UTMDACC, duration of all chemotherapy, and logarithm of primary tumor SUV at baseline and after chemotherapy; patients with missing values for that characteristic were excluded. ${ }^{1}$ Time-varying covariate; all patients begin in the 'No' group. Patients who undergo surgery are deleted from the 'No' group on the date of surgery. Then they start in the 'Yes' group on that date. One-year OS for 'Yes' patients is the time since surgery. $\mathrm{p}$ value in italics denotes that statistical significance was reached. 
Table 3. Multivariate Cox proportional hazards models for OS

\begin{tabular}{|c|c|c|c|c|c|c|}
\hline \multirow[t]{2}{*}{ Characteristic } & \multicolumn{3}{|c|}{$\begin{array}{l}\text { Full model } \\
(\text { death/total }=44 / 63)\end{array}$} & \multicolumn{3}{|c|}{$\begin{array}{l}\text { Reduced model } \\
(\text { death/total }=45 / 64)\end{array}$} \\
\hline & $\mathrm{HR}$ & $95 \% \mathrm{CI}$ & $\mathrm{p}$ value & $\mathrm{HR}$ & $95 \%$ CI & $\mathrm{p}$ value \\
\hline Chemotherapy duration (years) ${ }^{1}$ & 0.91 & $0.81,1.02$ & 0.10 & 0.90 & $0.80,1.01$ & 0.08 \\
\hline Dose of consolidation (>50 vs. $40-50 \mathrm{~Gy}$ ) & 1.58 & $0.77,3.25$ & 0.21 & & & \\
\hline Surgery $^{2}$ (yes vs. no) & 0.41 & $0.18,0.95$ & 0.04 & 0.37 & $0.16,0.85$ & 0.02 \\
\hline
\end{tabular}

HR = Hazard ratio. ${ }^{1}$ Duration of chemotherapy was required to remain in the model regardless of the significance level. ${ }^{2}$ Timevarying covariates; all patients begin in the 'No' group. Patients who undergo surgery are deleted from the 'No' group on the date of surgery and then start in the 'Yes' group on that date. $\mathrm{p}$ values in italics denote that statistical significance was reached.

Fig. 2. Nomogram predicting OS at the start of CRT.

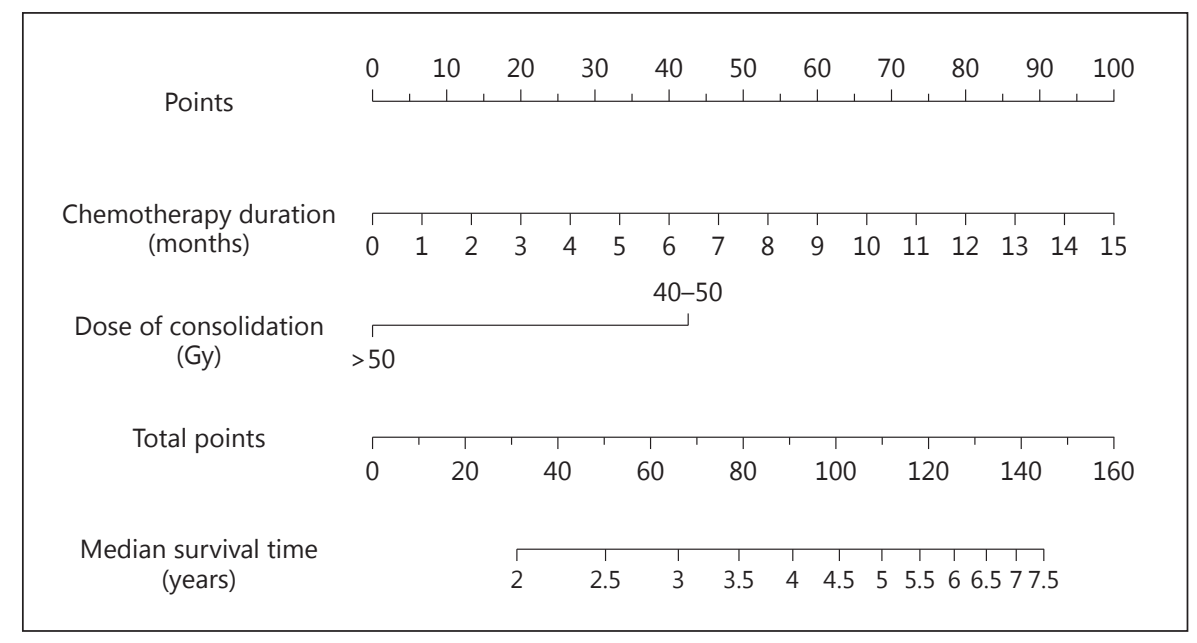

respond to the median OS time in years. Internal validation showed that the concordance index for the model was 0.61 .

\section{Discussion}

Prognosis of MGEAC is poor, with a median OS between 8.6 and 13.8 months $[5,13]$. However, some patients with MGEAC achieve favorable outcomes. In this analysis, several patients survived longer than 5 years but had no specific clinical variable that could prospectively identify them. Therefore, our multidisciplinary team could not identify them at their initial presentation but they could be selected based on their clinical course and the decision to administer local consolidation. Currently, there is no algorithm to help with this selection process.

We present one of the largest patient cohorts who first received systemic therapy and then consolidative local therapy. A major characteristic of these patients is that they have excellent tumor regression from systemic therapy, and the duration of response is unusually long ( $>6$ months). These patients also do not develop new metastases. However, since systemic therapy is not curative and the primary tumor is rarely eradicated by systemic therapy, it is rationale to selectively use local consolidation. Our preference is also to use CRT rather than surgery. The nomogram was developed to help construct selection of these patients. However, it should be emphasized that this nomogram is prognostic only, and it is also not yet validated.

It should be emphasized that our report has shortcomings given that it is a retrospective review of data from a single institution. However, since literature lacks guidance on this issue, we believe the results may be useful for other groups. We encourage more reports on this subject and improved awareness of the fact that even patients with stage IV disease can have long-term OS ( $>5$ years) with this type of approach. 


\section{Acknowledgements}

This study was supported by generous grants from the Caporella, Dallas, Sultan, Park, Smith, Frazier, Oaks, Vanstekelenberg, McNeil, Planjery, and Cantu Families, as well as from the Schecter Private Foundation, Rivercreek Foundation, Kevin Fund, Myer Fund, Dio Fund, Milrod Fund, and multidisciplinary grants from the UTMDACC, Houston, Tex., USA. It was also supported in part by the National Cancer Institute awards CA138671, CA172741, CA129926 (J.A.A.), and P30CA016672, and used the Biostatistics Resource Group.

\section{Disclosure Statement}

The authors declare that they have no competing interests.

\section{References}

1 Cancer facts and figures 2015. http://www. cancer.org/cancer/esophaguscancer/detailedguide/esophagus-cancer-key-statistics.

2 Siegel RL, Miller KD, Jemal A: Cancer statistics, 2015. CA Cancer J Clin 2015;65:5-29.

3 SEER Stat Fact Sheets: Esophageal cancer. http://seer.cancer.gov/statfacts/html/esoph. html.

4 Ajani JA, Bentrem DJ, Besh S, D’Amico TA, Das P, Denlinger C, Fakih MG, Fuchs CS, Gerdes H, Glasgow RE, et al: Gastric cancer, version 2.2013: featured updates to the NCCN Guidelines. J Natl Compr Canc Netw 2013;11: 531-546.

5 Ajani JA, D'Amico TA, Almhanna K, Bentrem DJ, Besh S, Chao J, Das P, Denlinger C, Fanta P, Fuchs CS, et al: Esophageal and esophagogastric junction cancers, version 1.2015. J Natl Compr Canc Netw 2015;13: 194-227.
6 Bang YJ, Van Cutsem E, Feyereislova A, Chung HC, Shen L, Sawaki A, Lordick F, Ohtsu A, Omuro Y, Satoh T, et al: Trastuzumab in combination with chemotherapy versus chemotherapy alone for treatment of HER2positive advanced gastric or gastro-oesophageal junction cancer (ToGA): a phase 3 , openlabel, randomised controlled trial. Lancet 2010, 376:687-697.

7 Lorenzen S, Thuss-Patience P, Al-Batran SE Lordick F, Haller B, Schuster T, Pauligk C, Luley K, Bichev D, Schumacher G, et al: Impact of pathologic complete response on diseasefree survival in patients with esophagogastric adenocarcinoma receiving preoperative docetaxel-based chemotherapy. Ann Oncol 2013;24:2068-2073.

8 Shariat SF, Karakiewicz PI, Suardi N, Kattan MW: Comparison of nomograms with other methods for predicting outcomes in prostate cancer: a critical analysis of the literature. Clin Cancer Res 2008;14:4400-4407.
9 AJCC: AJCC Cancer Staging Manual, ed 6. New York, 2002.

10 Kaplan EL, Meier P: Nonparametric estimation from incomplete observations. J Am Stat Assoc 1958;53:457-481.

11 Cox DR: Regression models and life-tables. J R Stat Soc Series B (Methodological) 1972;34: 187-220.

12 Harrell FE: Regression Modeling Strategies: with Applications to Linear Models, Logistic Regression, and Survival Analysis. New York, Springer, 2001.

13 Elimova E, Shiozaki H, Wadhwa R, Sudo K, Chen Q, Estrella JS, Blum MA, Badgwell B, Das P, Song S, et al: Medical management of gastric cancer: a 2014 update. World J Gastroenterol 2014;20:13637-13647. 